\title{
CONJUNCTIVAL ANGIOSCOPY*
}

BY

\section{PAUL WEINSTEIN AND JOSEPH FORGÁCS}

From the Department of Ophthalmology, Budapest University

AcCoRDing to Rollin (1934), Pletnava (1938), and Sédan and Sédan-Bauby (1949), the condition of the conjunctival vessels is a reliable guide to the state of the circulatory system in hypertonic individuals. Different types of conjunctival aneurysms (Fig. 1), for instance, have been associated with different diseases of the circulatory system (Miller, 1949), and more recently McCulloch and Pashby (1950) have described berry-shaped conjunctival dilatations in a considerable number of diabetic cases.

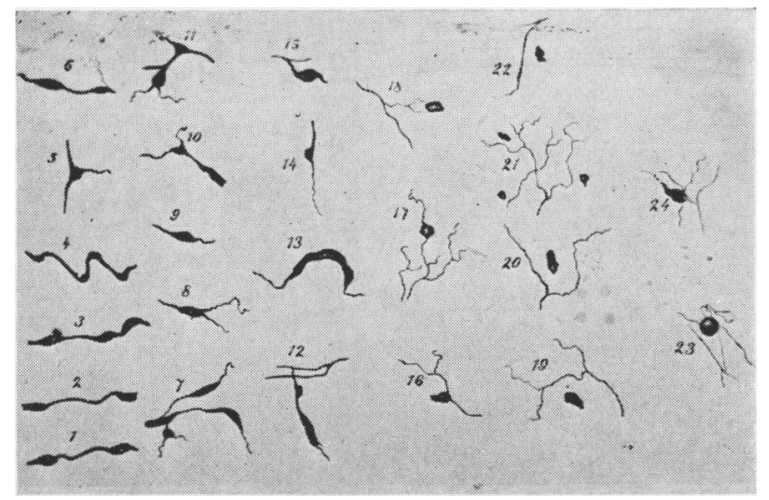

FIG. 1.-Ditterent types of conjunctival aneurysms in different diseases (after Miller, from Berliner, 1949). [1-12, arteriosclerosis ; 13-21, nephritis ; 23-24, leukaemia].

In order to secure further data we have made photographic records of pathological changes in the conjunctival vessels. For this purpose the photomicrographic apparatus of Leitz attached to a Haag-Streit slit lamp was used (time of exposure $0.1 \mathrm{sec}$. at 6 ampères, using $4.5 \times 6 \mathrm{~cm} . x$-ray film) and, as will be seen from the accompanying figures, photographs rich in detail were obtained.

* Received for publication March 20, 1951. 


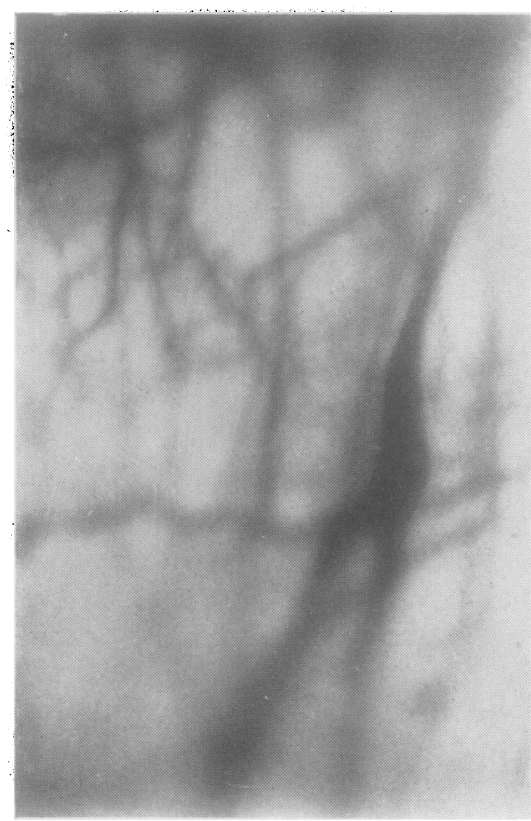

Fig. 2.-Saccular aneurysm in arteriosclerosis.

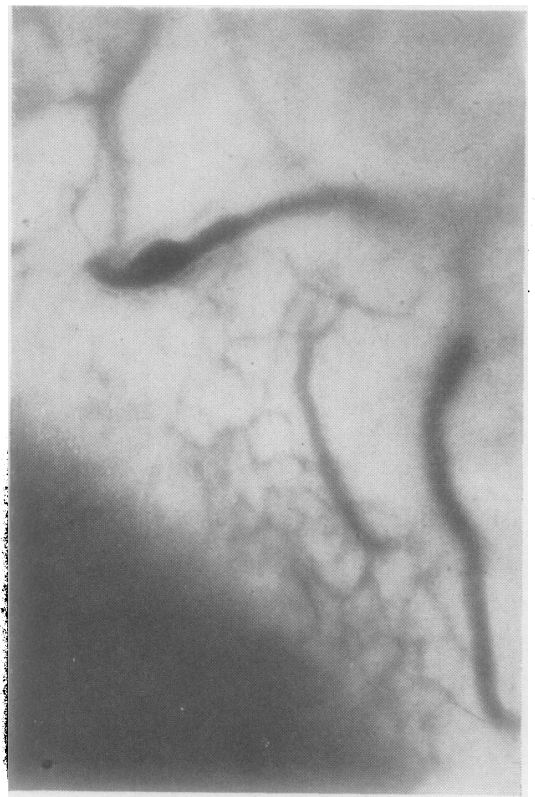

Fig. 3.-Fusiform aneurysm in hypertension.
Three forms of aneurysms could be distinguished; a saccular type occurring in cases of arteriosclerosis (Fig. 2) and situated usually at the bifurcation of the vessels, a fusiform type seen in cases of hypertension (Figs 3 and 4), and a berry-shaped type occurring mainly in diabetic subjects (Fig. 5). It should be emphasized, however, that these different types of vascular dilatations may be found occasionally in the conjunctivae of normal persons, their incidence increasing with advancing age. We are able to confirm the statement of McCulloch and Pashby that berry-shaped aneurysms occur in the conjunctival vessels in 55 per cent. of diabetic cases (Fig. 6). Furthermore, retinal

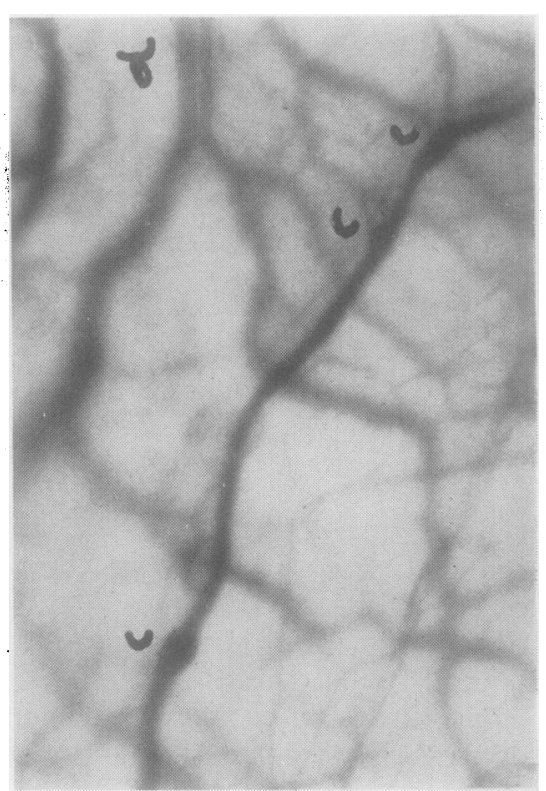

Fig. 4.-Fusiform aneurysms (C). d: v. aquea. 


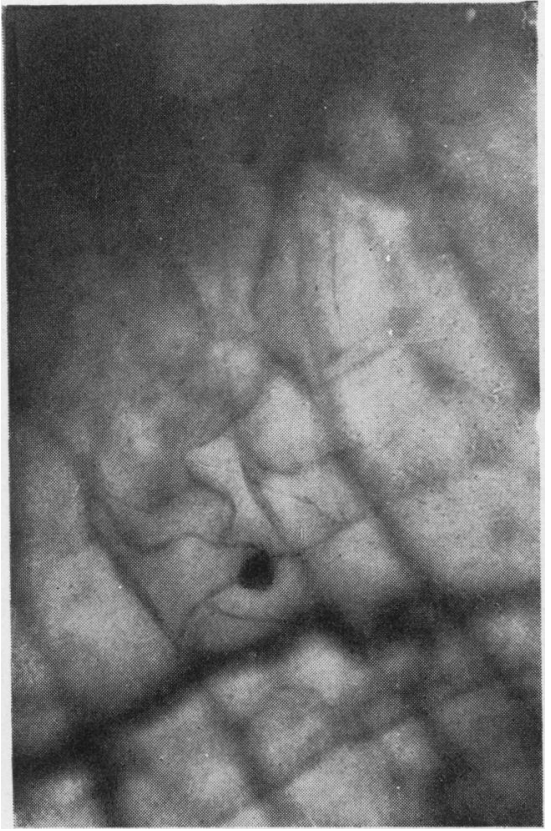

FIG. 5. Berry-like aneurysm in a normal case.

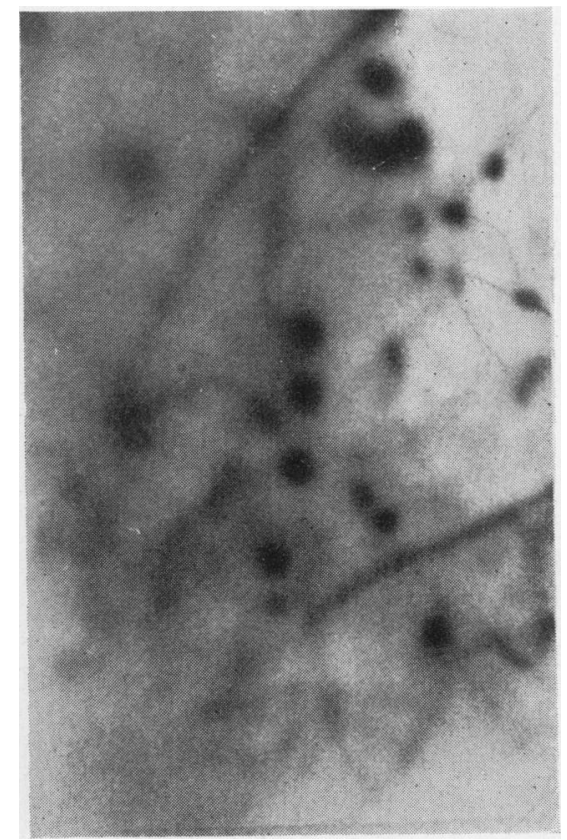

FIG. 6.-Berry-like aneurysms in diabetes.

micro-aneurysms, as described by Ballantyne and Loewenstein (1943), Ashton (1949), and Friedenwald (1950), were present in 20 per cent. of 150 diabetics, but the retinopathy was independent of the conjunctival aneurysms. It is interesting to note that in 70 per cent. of the diabetic cases with simultaneous retinal and conjunctival aneurysms, an abnormal electrocardiogram was present.

What is the significance of these aneurysms ? We believe that in attempting to answer this question certain hydromechanical rules may be applicable, especially since aneurysms may be found in conditions which cannot be regarded as pathological. Within the observational period of one week, a conjunctival aneurysm may change its shape. A saccular aneurysm, for instance, may become fusiform (Figs 7 and 8). The vessel adapts itself to the varying conditions in the circulation and the aneurysmal dilatation is thus an expression of a functional vasomotion (Zweifach, 1950). Kiss and Orbán (1950) have recently described " bulbiculi " in the venae vorticosae (Fig. 9), irregularities which cannot be regarded as pathological since they were found even in early youth; these too may be explicable on the same basis. According to Bernoulli's rule for liquids streaming within a tube, the product of the velocity and the pressure is constant at every crosssection of the tube. Thus at positions of dilatation, velocity is less 


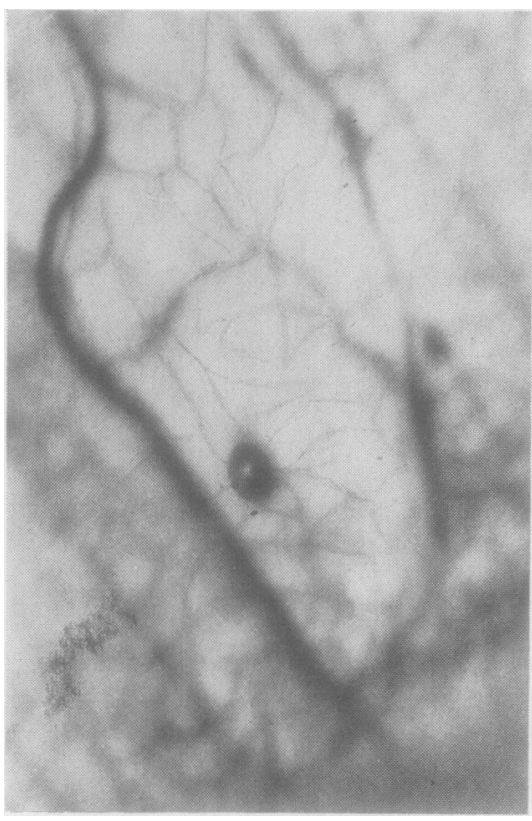

FIG. 7.-Ring-like aneurysm.

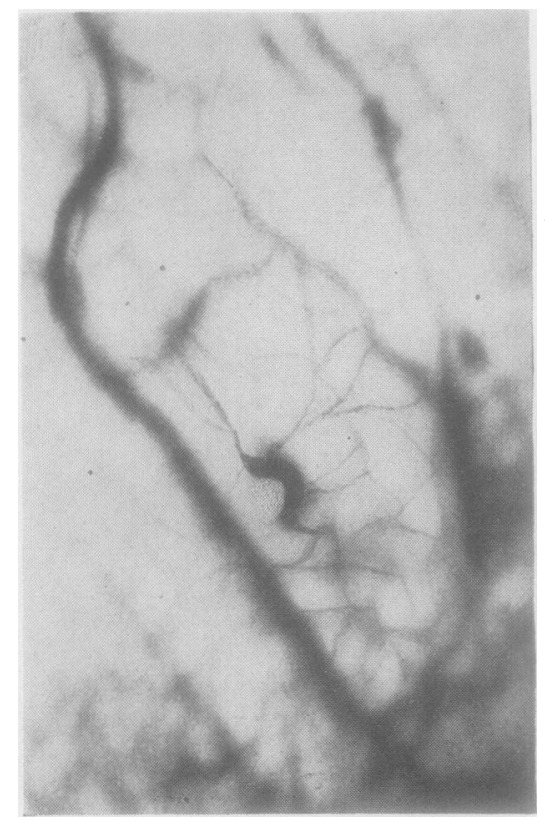

FIG. 8. Vasomotion of the aneurysm seen in Fig. 7.

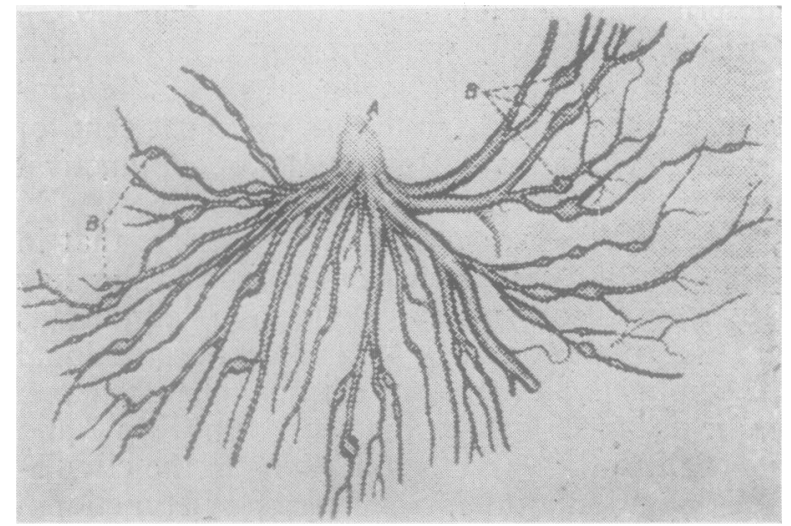

FIG. 9. Bulbiculus of venae vorticosae (after Kiss and Orbán, 1950).

and pressure greater and vice versa. In the case of the arterial circulation, this means that circulation within capillaries leading from a dilated vessel, takes place at a higher pressure than in those leading from constricted vessels. In venous dilatations, mainly occurring in diabetes, Venturi's rule applies, which states that the pressure of a fluid flowing through a constriction is less than that on 
either side; a vessel joining at the site of the constriction would, therefore, be subjected to suction. It will thus be seen that aneurysmal dilatations, both on the arterial and venous side, may serve as equilibrating reservoirs. Fluid injected intermittently into a U-shaped rigid tube emerges intermittently at both ends, but if a rubber tube be inserted into one of the branches, which now becomes capable of extension, the streaming within this branch becomes continuous while remaining intermittent in the other. Similarly, aneurysms may serve to ensure an even blood supply within the capillaries.

\section{REFERENCES}

Ashton, N. (1949). British Journal of Ophthalmology, 33, 407.

Ballantyne, A. J., and Loewenstein, A. (1943). Trans. ophthal. Soc. U.K., 63, 95. Friedenwald, J. S. (1950). Amer. J. Ophthal., 33, 1187.

Kiss, F., and Orban, T. (1950). Szemészet, 87, 74.

MCCulloch, C., and PASHBY, T. J. (1950). British Journal of Ophthalmology, 34, 495. Miller (1949). Quoted by M. L. Berliner, "Biomicroscopy of the Eye", p. 133. Hoeber, New. York.

Pletneva, N. A. (1938). XV. Conc. Ophthal. Egypt 1937, 2, 150.

Rollin, A. (1934). Bull. Soc. Ophtal. Paris, 46, 628.

SÉDAN, J., and SÉDAN-BAUBY, S. (1949). Bull. Soc. Ophtal. France, p. 228.

ZWEIFACH, B. W. (1950). Trans. 3rd Conference on Factors regulating Blood Pressure, 1949, p. 13. Josiah Macy Jr. Foundation, New York. 